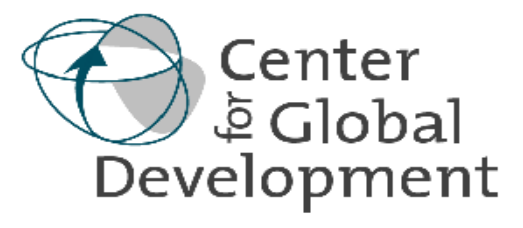

Working Paper Number 160

February 2009

A Fresh Look at Global Governance:

Exploring Objective Criteria for Representation

Enrique Rueda-Sabater, Vijaya Ramachandran, and Robin Kraft

\begin{abstract}
The geopolitical world of the 21 st century is very different than that of the postWorld War II era. In this new world order, what constitutes a system of global governance? We argue that it has to balance representation, which is made credible by the inclusion of key parts of the global community, and effectiveness, which means involving as small a number of actors as possible while having access to the resources - and clout - to turn decisions/intentions into action/results. In this paper, we propose simple, fundamental criteria—based on global shares of GDP and population-around which global governance might be organized. We analyze the role that these criteria would assign to different countries and compare them with some of the key components of the system of governance currently in place- the Bretton Woods institutions and the United Nations. We also examine the implications of our analysis for membership in the G-20 and the OECD. We find major disparities, which suggest the need for fundamental changes in sharp contrast to the incremental changes that are currently being considered. Overall, our analysis points to the need for a more comprehensive approach, and for much more than incremental solutions.
\end{abstract}

The Center for Global Development is an independent, nonprofit policy research organization that is dedicated to reducing global poverty and inequality and to making globalization work for the poor. This paper was made possible in part by funding from the Australian Agency for International Development.

Use and dissemination of this Working Paper is encouraged; however, reproduced copies may not be used for commercial purposes. Further usage is permitted under the terms of the Creative Commons License. The views expressed in this paper are those of the author and should not be attributed to the board of directors or funders of the Center for Global Development.

www.cgdev.org 
Enrique Rueda-Sabater, Vijaya Ramachandran, and Robin Kraft. 2009. "A Fresh Look at Global Governance: Exploring Objective Criteria for Representation."

CGD Working Paper 160. Washington, D.C.: Center for Global Development. http://www.cgdev.org/content/publications/detail/1421065/ 


\title{
A Fresh Look at Global Governance: Exploring Objective Criteria for Representation*
}

\author{
Enrique Rueda-Sabater \\ Vijaya Ramachandran \\ Robin Kraft
}

February 2009

\begin{abstract}
The geopolitical world of the $21^{\text {st }}$ century is very different than that of the post-World War II era. In this new world order, what constitutes a system of global governance? We argue that it has to balance representation, which is made credible by the inclusion of key parts of the global community, and effectiveness, which means involving as small a number of actors as possible while having access to the resources - and clout - to turn decisions/intentions into action/results. In this paper, we propose simple, fundamental criteria-based on global shares of GDP and population-around which global governance might be organized. We analyze the role that these criteria would assign to different countries and compare them with some of the key components of the system of governance currently in place-the Bretton Woods institutions and the United Nations. We also examine the implications of our analysis for membership in the G-20 and the OECD. We find major disparities, which suggest the need for fundamental changes in sharp contrast to the incremental changes that are currently being considered. Overall, our analysis points to the need for a more comprehensive approach, and for much more than incremental solutions.
\end{abstract}

\footnotetext{
* We are grateful to Michael Barzelay, Colin Bradford, Nancy Birdsall, Jo Marie Griesgraber, Roger King, Johannes Linn, Steve Radelet and seminar participants at the Center for Global Development for helpful comments and suggestions. The views presented in this paper are solely those of the authors.
} 
Enrique Rueda-Sabater, Vijaya Ramachandran, and Robin Kraft. 2009. "A Fresh Look at Global Governance: Exploring Objective Criteria for Representation."

CGD Working Paper 160. Washington, D.C.: Center for Global Development. http://www.cgdev.org/content/publications/detail/1421065/ 


\section{Introduction}

The world has become more interdependent and yet no progress is being made towards an effective, coherent system of global governance. The various pieces of the fragmented system in place (from the UN to the Bretton Woods institutions at the more formal end to the G7, G8 at the more informal end) have not kept pace with change in the world. Many scholars, policymakers and journalists argue that the institutions established after World War II have lost much of their relevance and do not add up to the system that managing the world's growing interdependence demands. Broadly speaking, we need a global governance system that reflects the geopolitical and economic world of the $21^{\text {st }}$ century.

The recent crisis (after some months of decoupling denial) underscored the world's economic interdependence. When a platform was needed for high-level coordination none of the formal ones were up to the task ... and a variation on the informal G20 mechanism was brought into service. While clearly an improvement over the G7, does it make sense to simply resort to an informal mechanism that happens to have been set in improvised motion during the previous financial crisis, instead of using the opportunity to systematically look at key criteria for global governance and allow them to drive the establishment of a new system?

What are the goals of global governance? There are a number of things that are critically dependent on a well-functioning system of global governance-the delivery of global public goods, the deployment of resources to coordinate and provide help during times of crisis and also to promote sustainable growth. Global governance in the $21^{\text {st }}$ century needs to be able to provide a context where interactive knowledge networks thrive (as opposed to “one way" technical assistance) and where intangible assets such as the leadership to convene relevant groups of countries to address issues such as climate change or pandemics come naturally.

We propose to take a fresh look at what could be the "holding company" of an effective global governance system and consider the implications of applying the ensuing criteria to the world of today and of the foreseeable future. The purpose is not to define the governance system of any single institution. Nor do we define the mechanisms of decision-making within individual institutions. Rather, the purpose is to provide an over-arching structure for global governance. ${ }^{1}$ We allow ourselves to be constrained in one regard-by considering only criteria that revolve around nation states.

It is worth noting at the outset that many proposals are in the works to improve global governance. Much of the effort has revolved around the Bretton Woods institutions and a lot of ink has been spilled on the UN Security Council. The dilemma that these proposals face is that they have to walk a fine line between tactical issues (the viability of reform) and fundamental problems (the disparity in representation pointing to the need for a major overhaul). The way this dilemma is generally solved in high-visibility proposals is by adopting an incrementalist approach. This raises big questions - do the governance reform proposals that appear viable for individual institutions exacerbate rather than overcome existing limitations? Could small wins of

\footnotetext{
${ }^{1}$ We recognize that an effective system of global governance is determined by more than the right membership structure. But membership is at the very center of a good system and is therefore the focus of our work.
} 
incrementalist reductions in what will remain a big gap in credible governance lead in the longer term, to big losses in the ability of the world to manage pressing issues of interdependence?

\section{What criteria?}

What would constitute a system of "good" global governance? We propose to think about as the criteria for national representatives to be offered a seat at the global governance table. This group would have to offer a combination of representation, which means including the bulk of the global population, and effectiveness, which implies having access to the resources-and clout— to turn decisions/intentions into action/results.

Before going into the criteria, though, a point of process. To have lasting credibility, a system of global governance has to be based on transparent criteria. Neither a 'club' approach (à la OECD) not a 'hosted' approach (such as the G7/8/20) would meet this transparency requirement.

The first criterion we propose goes to the root of democracy-rule of the people. It is quite a different thing from 'statocracy' or rule by sovereign governments. Isn't recent economic history--the rise of China and India, for example--a vindication that we cannot forget people? For a system of governance to be credible, people must be a central component-maybe even the make-or-break criterion for representation?

The second criterion reflects pragmatism—based on experience with effective multilateral interventions-also suggests the importance of another fundamental criterion as there is no doubt that economic resources are key as well. The combination of access to resources and a reasonably small number of actors around the table are likely to be a sound basis for effectiveness. The size of GDP would seem to offer a good proxy for should be a central component of any global governance mechanism--the make-or-break for effectiveness?

These two criteria appear not only to be superior to any other options but have the virtue of simplicity. But we must allow also allow for a third criterion-universality. It can also be seen as a form of minority rights protection and entails some form of representation of nation states, regardless of their size. This is the way the world is currently organized and, in addition, national governments are the usual means for executing decisions but the challenge will be doing so without creating decision paralysis. ${ }^{2}$

Based on these factors, it is useful to think about the ideal system of global governance as having to reach a balance between these three perspectives. First, people (democracy); second, economics (resources); and third, nation states (universality plus execution mechanisms). This can be represented by the simple schematic below.

\footnotetext{
${ }^{2}$ Arguments can be made that countries which are democratic or have higher ratings on the World Bank's CPIA scale or the UN's Human Development Index should be given greater weight. We recognize these arguments but keep our criteria very simple and tractable.
} 


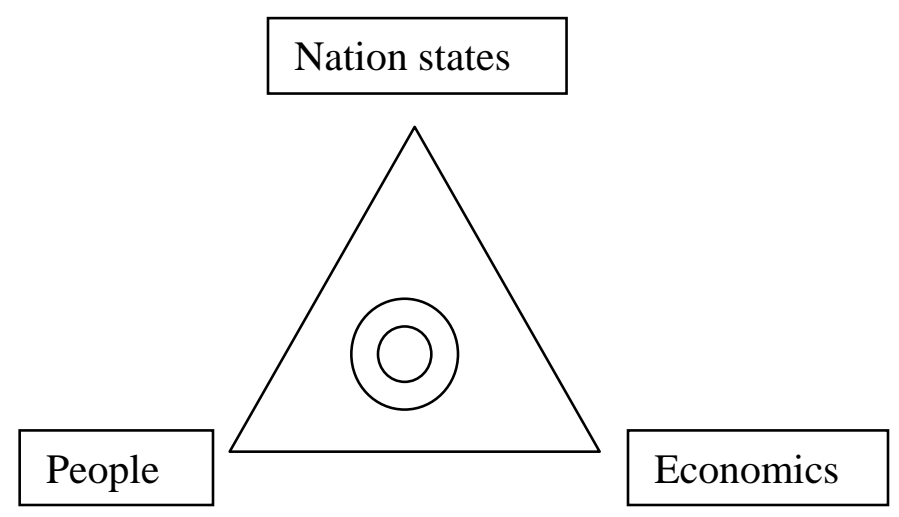

An earlier effort was made to use a similarly pragmatic approach to determine representation on the United Nations Security Council. In 2005, Kemal Dervis (now Administrator of UNDP) looked at weighted indexes of GDP and population to establish a basis for global governance. Because his purpose was specifically to propose an approach to determine which countries sit on the UN Security Council, he also added military capacity to the mix (Dervis, 2005). More recently, a region-based "meta-process" has been proposed with regard to the Bretton Woods system, for determining a new governance structure (Mattoo and Subramanian, 2008), with regional representation by as many countries in rank order so that 50\% of each region's GDP is represented, with a limit that no region can be represented by more than three countries. Finally, some have advocated fixes aimed at specific institutions. One example is a "double-majority" approach to voting at the IMF that would require approval of actions by a majority of states as well as a majority of shares (Chowla et al, 2007).

One can imagine more complex systems, with more variables such as military capacity, global trade shares, savings rates, or efforts to reduce global warming. Rather than nation states, we might even think of non-state actors which are engaged in large-scale service delivery in some countries and regions. But thinking ahead about managing interdependence, we argue that GDP and population are the key factors. And in the end, very little is left out after you take them into account ... except perhaps governments! In addition, our analysis is about credible global governance systems--the more complex the formula, the less likely it will earn that credibility widely.

\section{Current Institutions from the Perspective of the Triangle}

Let us look briefly at some of the key institutions that are generally seen as elements of the system that currently approaches an effort at global governance.

The United Nations comes first to mind and is widely regarded as a representative body. But the facts remind us that the General Assembly (one country, one vote) is far from democratic and, instead, based on a purely statocratic logic (while the Security Council does take might into 
account). From some perspectives hand, the absurdity of this type of representation is staggering-the Prime Minister of St. Lucia represents a country but only half the number of people $(165,000)$ as the mayor of the Mexican town of Merida $(350,000)$. The "princes" of Andorra also a member of the United Nations represent far, far fewer $(83,000)$ than the governor of Andhra Pradesh (more than 100 million but an Indian state rather than a country) and so on.

Senates all over the world honor a similar approach — though maybe with much less striking

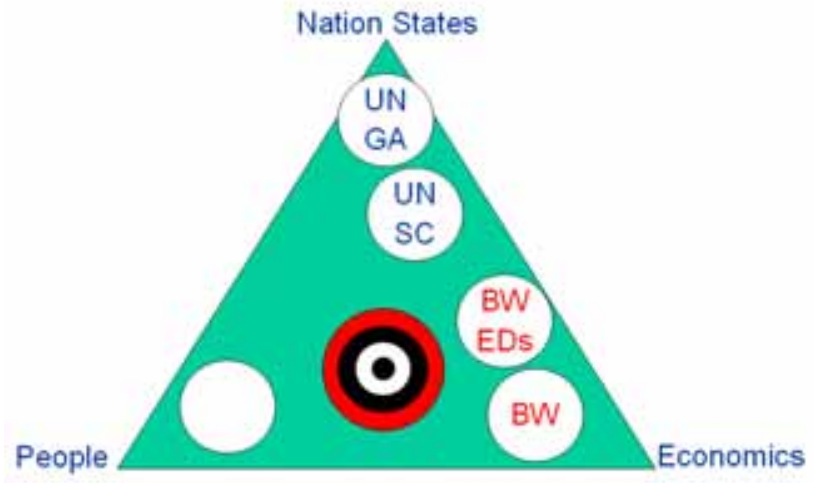
differences in size (compare for example, the ratio of the populations of the largest to smallest states in the US (70:1) with that of the largest to the smallest UN members $(100,000: 1){ }^{3}$

The Bretton Woods institutions (the World Bank and the International Monetary Fund with similar approaches prevailing in the regional development banks) had a clear focus on economic power from the start and representation was determined accordingly. As membership has grown (after China joined and then with the break-up of the Soviet Union), the Bretton Woods governance has become more democratic while trying to maintain economic representation. But as the world economy has evolved, the Bretton Woods institutions' rigid mechanisms for allocating shares has kept them from maintaining - much less increasing - that same capacity for representation. The changes that would be required to achieve a reasonable measure of economic representation are way beyond what the major shareholders are prepared to contemplate (as recent proposals underscore). Finally, the Executive Boards of these institutions reflect a hybrid-but informal-mechanism and very incremental changes now underway seem to be moving towards statocracy more than towards democracy or effectiveness. It is not clear why, for instance, a World Bank that looks more like the UN would be more effective!

Notice the gap on the lower left hand side of our triangle ... there is no international institution whose governance system is driven by people! We could keep populating the triangle with other institution with global or at least international mandates but it would not change the picture very much.

\section{An objective application of the two main criteria}

Any formula that reflects people and resources would need to be based in careful analysis of these factors, but would also have to be forward-looking. Therefore, we look ahead — to 2020 —

\footnotetext{
${ }^{3}$ The ratio for the US is the population of California (36 million) to Wyoming $(515,000)$. The "great compromise" in the US was to create a bicameral system for representation. But in the case of the global system, this is much harder given the very large ratios between the largest and smallest countries. For the UN, we compare the ratio of China (1.3 billion) to Nauru, one of the UN's smallest members.
} 
to avoid obsolescence of any influence-sharing system. We use simple projections of GDP and population to construct a global governance scenario for $2020 .^{4}$

GDP shares and projections are widely used in discussions of trends in economic might but are often subject to assumptions. Demographic trends are somewhat more predictable. Both are important for our purposes--we find it particularly useful to look at the world combining the two criteria to produce lists of countries above a significant threshold for the global share of either GDP or population. ${ }^{5}$ Figures $1 \mathrm{a}$ and $1 \mathrm{~b}$ show the list of countries that account for at least 2 percent of GDP in 2008 and in 2020. Figures 2a and 2b do the same for the share of population.

Figure 1a and 1b: Countries with GDP> 2 percent of world GDP in 2008 and 2020
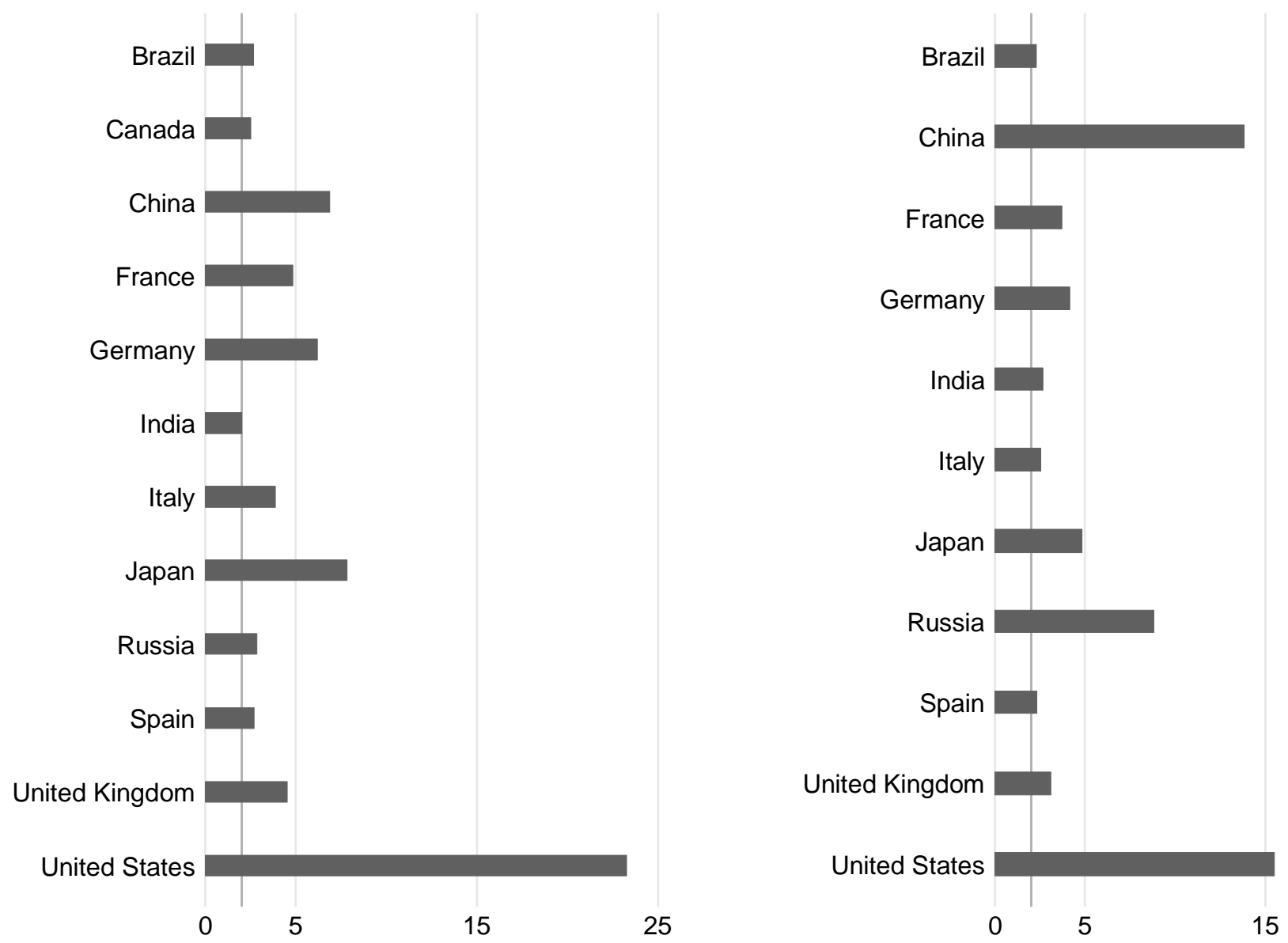

\footnotetext{
${ }^{4}$ Comprehensive projections are generally hard to come by, and the methodology is usually not very transparent. For this analysis, two approaches are possible, using the IMF's GDP (and/or GDP growth) projections to 2013 and then extrapolating out to 2020. We can either use the Compound Annual Growth Rate (CAGR) from 2010 - 2013 or from 2000 - 2013, to project out to 2020. We use the former. This gives us substantial country coverage (181 countries) and we can also compare the relative sizes and adjust growth rates as necessary by triangulating with other sources (such as the Deutsche Bank data). The country level GDP and GDP growth rates from the IMF to 2013 are in the latest IMF World Economic Outlook database (October 2008): http://www.imf.org/external/pubs/ft/weo/2008/02/weodata/index.aspx ${ }^{5}$ The correlation coefficient of GDP with population is 0.398 ; we find this to be sufficiently low to focus on these two variables separately.
} 
Figure 2a and 2b: Countries with Populations > 2 percent of World Population in 2008 and 2020
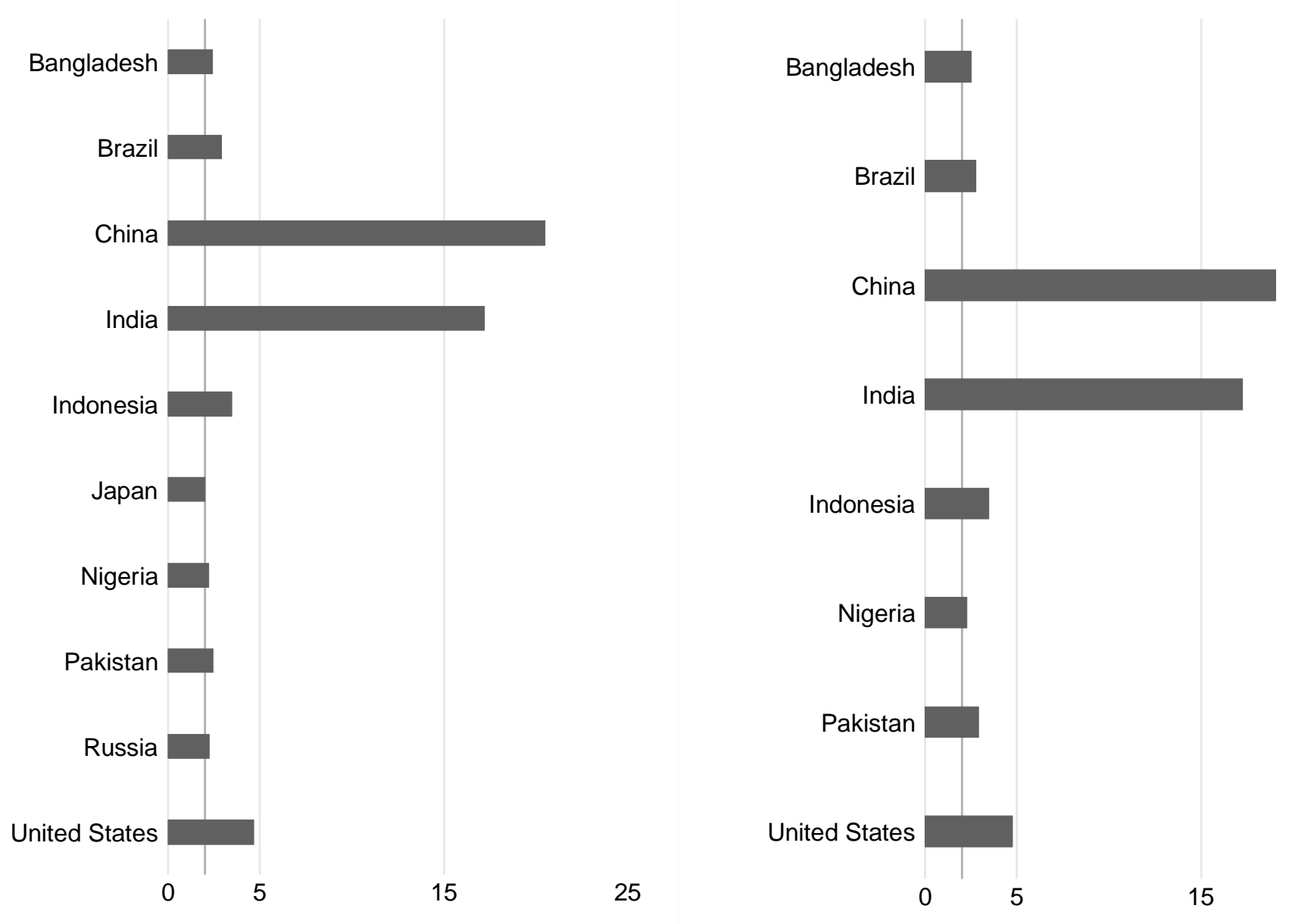

Figures 3a and 3b combine the two criteria to determine a list of countries that would need to be individually represented at the global governance table, now and in 2020 . We chose $2 \%$ as the threshold after carrying out sensitivity analyses of higher and lower thresholds keeping two objectives in mind: the list had to be as short as possible (to make the table dynamics manageable) and ensuring that the countries in the list account for the bulk of people and economic resources in the world (or conversely, that the "rest of the world" does not account for a large residual after the listed countries are taken into account). 
Figure 3a and 3b: The 2\% Club of Global Governance in 2008 and in 2020 (GDP and population shares as percentage of world totals)
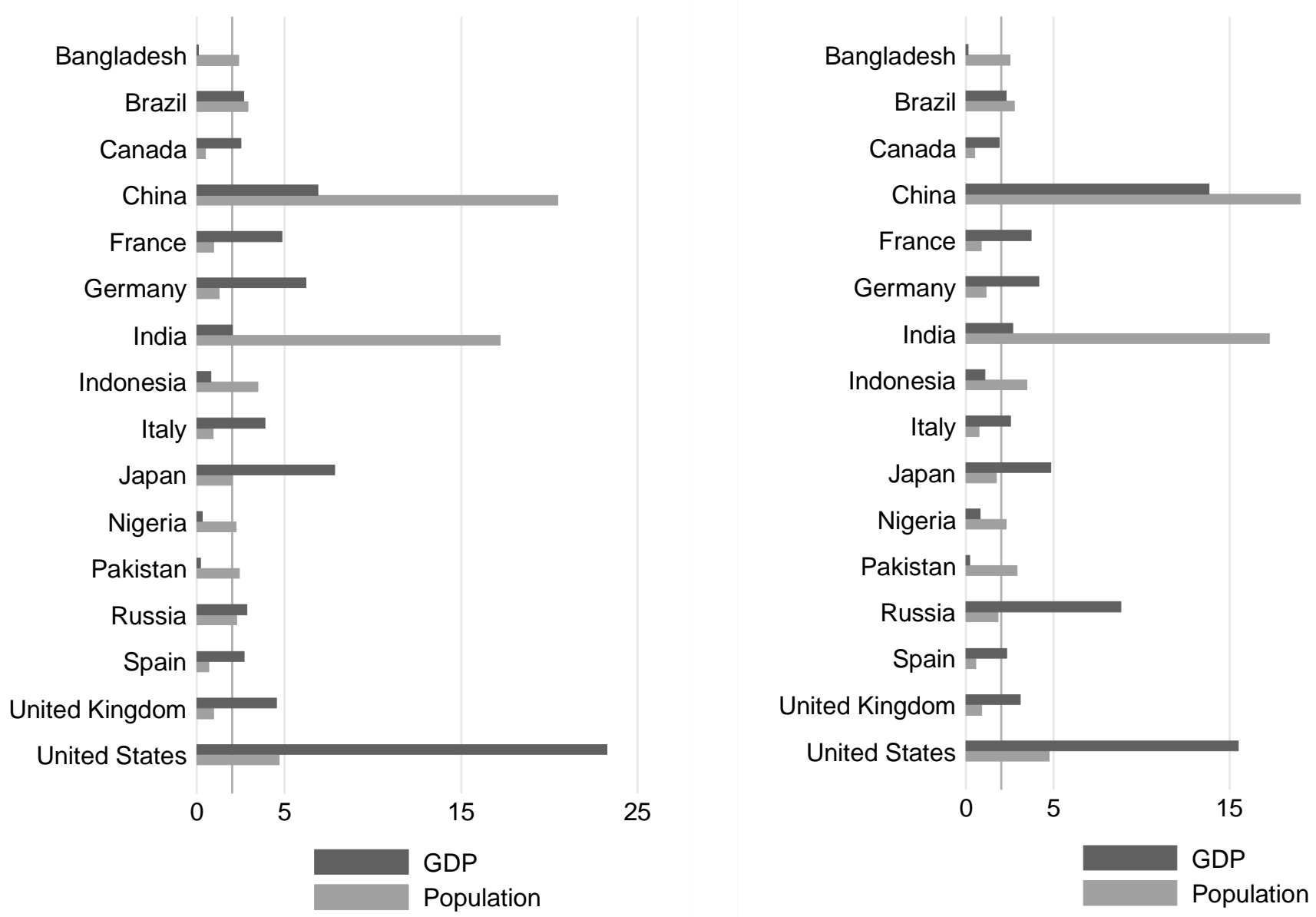

This simple exercise shows that there are currently 16 countries which meet our criteria of having either a GDP share greater than 2 percent or a population share greater than 2 percent. ${ }^{6}$ These 16 countries account for $72 \%$ of GDP and $65 \%$ of population in 2008. In 2020, this number would be reduced to 15 as Canada is projected to slip below a 2 percent share of GDP (Table 1). These 15 countries are expected to account for 66\% of GDP and 63\% of population in 2020. Hence, in all cases the "rest of the world" share remaining after the individual, core countries are taken into account amounts to well under $40 \%$ of either GDP or people-both in current terms and in the 2020 projections.

\footnotetext{
${ }^{6}$ It is interesting to see that China, India, Brazil, Japan and the United States cross both thresholds i.e. their GDP and population shares are greater than 2 percent of world totals. This is also the case for Russia in 2008 but not in 2020.
} 
Table 1: Countries that have either GDP or Population $>2 \%$

\begin{tabular}{|l|l|}
\hline GDP or Population $>2 \%$ in 2008 & GDP or Population $>2 \%$ in 2020 \\
\hline Bangladesh & \\
\hline Brazil & Bangladesh \\
\hline Canada & Brazil \\
\hline China & China \\
\hline France & France \\
\hline Germany & Germany \\
\hline India & India \\
\hline Indonesia & Indonesia \\
\hline Italy & Italy \\
\hline Japan & Japan \\
\hline Nigeria & Nigeria \\
\hline Pakistan & Pakistan \\
\hline Russia & Russia \\
\hline Spain & Spain \\
\hline UK & UK \\
\hline US & US \\
\hline TOTAL (16) & \\
\hline $72 \%$ GDP & Total (15) \\
\hline 65\% Population & $66 \%$ GDP \\
\hline & $63 \%$ Population \\
\hline
\end{tabular}

To continue with our analysis, we propose taking as individual actors in a global governance system all countries that pass the threshold either currently or in 2020-surprisingly, the difference between the two lists is only Canada, which does not make the cutoff in 2020. This group of countries accounts for the bulk of the world's economy and population and therefore serves as a good basis for thinking about key actors — at the country level — that would need to be at the core of any system of global governance.

Different readers will quickly focus on inclusions or absences of interest to them. Compared to the G20, for instance, the absence of South Africa and the inclusion of Nigeria (which is rarely present at these venues and qualifies on population grounds) are noticeable. Saudi Arabia does not make either of the cutoffs but among oil exporters Russia and Nigeria do. Argentina and Mexico do not appear in the list (neither do other Spanish-speaking American countries) but Spain does qualify on GDP grounds (both current and projected to 2020). Importantly, though, the point of this exercise is not to focus on which country is in or out but on a set of transparent rules that would lead to more effective engagement on a dynamic basis - the list of countries could change over time with economic and demographic trends, and perhaps even through mergers of countries!

What about the rest? The activist Bob Geldof has articulated what many people and communities around the world feel, when he argued prior to the G20 summit in Washington in November 2008, that reform "cannot simply come in the form of a different carve-up between countries that have newly acquired more power and those that have always had it...reform of the global economy will not work until all are connected and involved” (Geldof, Financial Times, November 2008). 
For a global governance system to be truly representative, it must also deal in some form with universality. But instead of allowing that notion to cripple the effectiveness of the governance system, an alternative approach might be something akin to the "protection of minority rights" which is often considered to be best practice with regard to corporate governance. In the search for a way of characterizing the world that could provide a basis for incorporating notions of universality and minority rights, we (exceptionally) stay with tradition-taking into account the fact that the regional groupings we propose have 'traction' indicative of natural constituencies. Organizing the world in five regions, the remaining GDP and population shares show that the countries outside the core group are reasonably balanced, as described in Table 2.

Table 2: GDP and population shares of the 5 regional groupings of remaining countries

\begin{tabular}{|l|r|r|r|r|}
\hline & $\begin{array}{l}\text { GDP } \\
\text { share } \\
2008\end{array}$ & $\begin{array}{l}\text { GDP } \\
\text { share } \\
2020\end{array}$ & $\begin{array}{l}\text { Population } \\
\text { Share } \\
\text { 2008 }\end{array}$ & $\begin{array}{l}\text { Population } \\
\text { Share } \\
2020\end{array}$ \\
\hline Remaining Africa & 1.4 & 1.9 & 9.6 & 10.4 \\
\hline Remaining Europe & 4.4 & 6.8 & 5.6 & 6.2 \\
\hline Remaining MENA/S.Asia & 5.1 & 4.9 & 6.5 & 6.5 \\
\hline Remaining Americas & 13.1 & 13.0 & 6.7 & 6 \\
\hline Remaining E. Asia/Pacific & 4 & 7 & 5.7 & 6.7 \\
\hline TOTAL & 28 & 33.7 & 34.0 & 35.7 \\
\hline
\end{tabular}

In sum, we present a 'map' of the world in 2008 with 21 components that have critical meaning for governance-16 individual countries + 5 regional groupings (Americas, Europe+, Middle East/South Asia, Africa, East Asia/Pacific). The 2020 projections would alter this configuration somewhat - they provide an idea of how the system would need to be provided with some flexibility, but also underscore the basic stability of the approach. Appendix 1 carries out an analysis of countries at a1percent threshold which is more inclusive on the one hand but may lead to real problems of coordination on the other.

Using these 21 components, we can now compare how existing mechanisms for global representation fare in terms of effectiveness and representation, with the model of global governance described above. For simplicity's sake we use the UN and the Bretton Woods systems to characterize the present situation. We also look at the current membership arrangements of the G20 and the OECD with the criteria of representation, effectiveness and universality in mind.

\section{Fragmented Incrementalism is Not the Answer}

The main goal of our paper is to propose a set of criteria on which to build a credible platform for global governance. The analysis carried out for that purpose also highlights the limitations and biases of existing proxy mechanisms for global governance and the inadequacy of fragmented and incrementalist solutions to fill the existing gaps in global governance. In light of the extent of disparities between governance principles and practice in the main international institutions it is hard not to be concerned with incremental approaches. In light of the power re- 
distribution restrictions entrenched in the rules of individual institutions, it is hard not to be concerned with fragmented approaches to governance reform.

We illustrate the disparities by looking at the UN General Assembly (voting power equal to 1/192 per country) and at the Bretton Woods institutions (using as voting shares a simple average of World Bank and IMF). We then compare the relative voting power of countries and country groups in these institutions with global shares of population and GDP described above, as show in Figures 4 and 5. To ensure that this is not a rear-view mirror analysis, we use current data as well as 2020 projections. The combination of the cross-sectional country comparison and longitudinal analysis to 2020 provides a good illustration of the types of gaps that need to be filled and of the biases that have crept into the existing system, with respect to more balanced or principle-based global governance options.

While recognizing that the "holding company" model described in the previous section might not literally apply to the Bretton Woods or any other individual institution, it is useful to highlight how far these institutions are from a criteria-based system. Who is overrepresented; who is underrepresented ... and what are the implications?

The charts below (Figures 4 and 5) are self-explanatory but it is worthwhile to highlight a few points: ${ }^{7}$

Compared to economic size, all major powers are hugely underrepresented in the UN but there are even a number of surprises with respect to the Bretton Woods institutions:

- The US is now slightly under-represented in the Bretton Woods voting system and will become slightly over-represented by 2020 while Canada is already overrepresented and will become more so.

- Similarly, major European countries (France, Germany, Italy, Spain and the UK) as well as Japan are currently slightly under-represented but will become over-represented by 2020.

- Brazil, China, Mexico and Russia are now under-represented and will become severely underrepresented by 2020 without a very major overhaul of Bretton Woods voting shares.

- India is not obviously underrepresented currently but will become significantly so by 2020 .

Compared to population, the country story is a simple one. All major countries are democratically underrepresented in the 'statocracy' that is the UN system of governance-and (contrary to myth) less so in the Bretton Woods institutions. Conversely the regional groupings (most extremely Africa and Europe) are, without exception, democratically overrepresented in the UN voting system.

\footnotetext{
${ }^{7}$ The threshold analysis was also done using PPP numbers. This generates a slightly different group of countries and is available from the authors upon request. Our purpose is not to identify countries but to suggest a methodology that is both representative and effective.
} 
Figure 4: The 2\% Club vs. Current Bretton Woods and UN Voting Shares—2008 and 2020 (GDP and population shares vs. current voting shares)
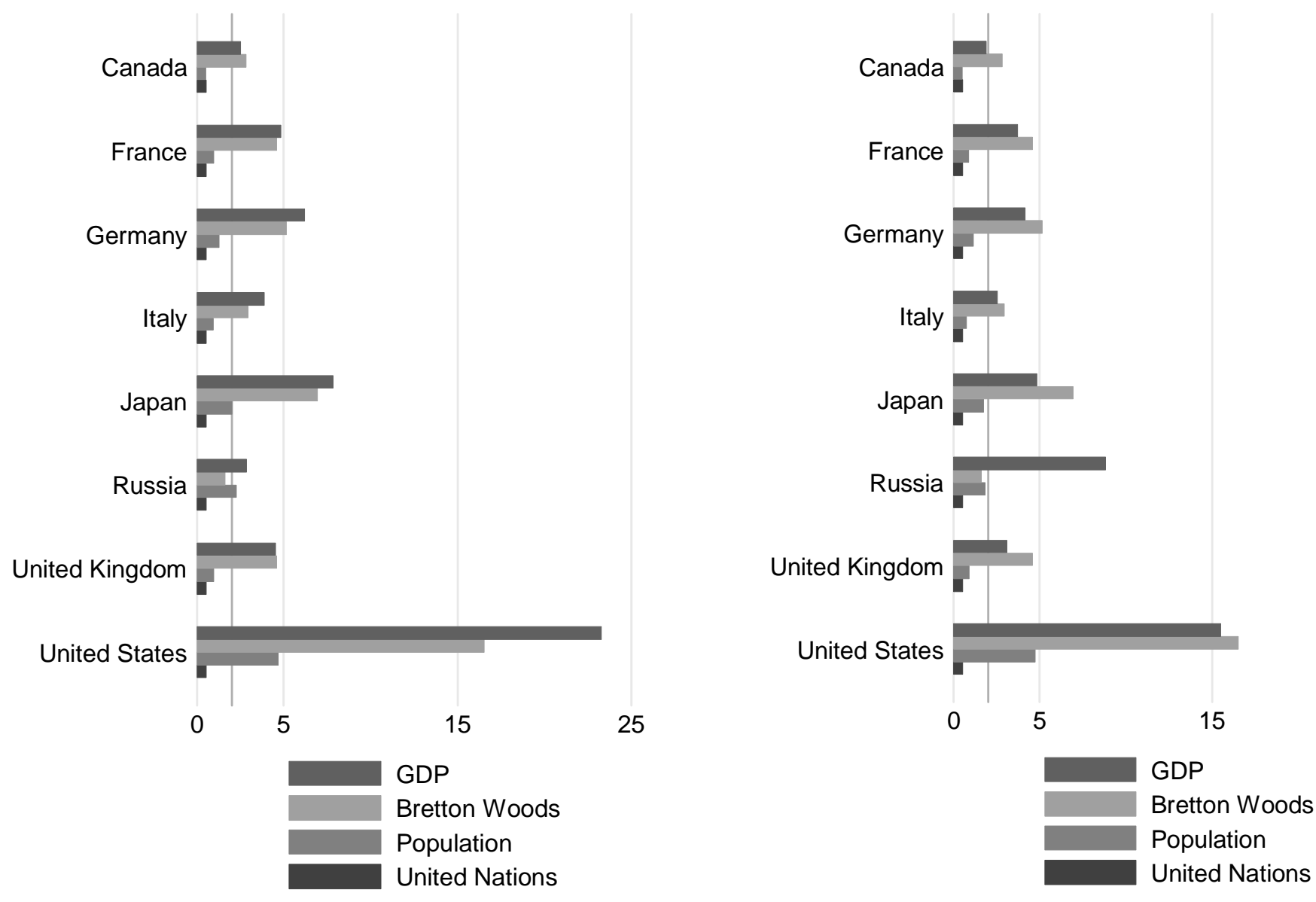
Figure 5: The 2\% Club in 2020 vs. Bretton Woods and UN Voting Shares—2008 and 2020

(GDP and population shares vs. current voting shares)
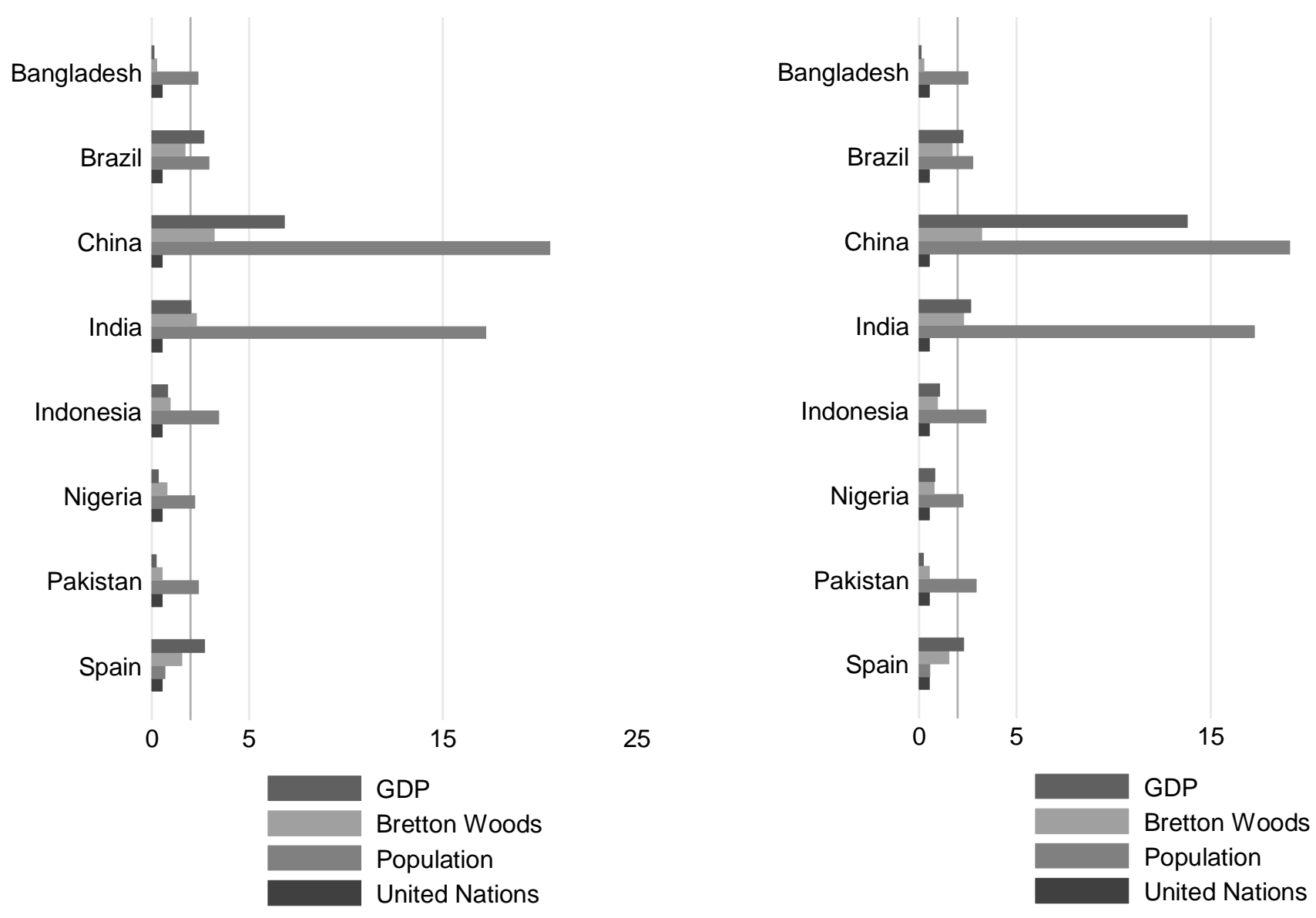

The discussion thus far has revolved around the importance of having the largest countries represented-and the bulk of the global GDP and population thus represented around the tablebut as we mentioned earlier, global governance needs to be also concerned with universal credibility. We presented regional groupings as the foundation of a transparent system in which smaller countries play a role (attempting to achieve a measure of universal representation as well as protection of minority — or, in this case, small states_rights) ... without creating a huge assembly and giving any country the right to paralyze the pursuit of global solutions.

Drawing from experience in inter-governmental relationships and from a number of proposals under discussion, we argue that these groupings offer a good avenue for thinking about the representation vs. effectiveness dilemma. Hence, we will consider in this analysis how these groupings fare as we seek a system to provide representation to all countries.

Comparing the GDP and population shares of the regional groupings of "remaining" countries to their voting shares in the Bretton Woods institutions and in the UN underscores the overrepresentation in the UN of some groupings from a democratic perspective (not surprising given how the individual countries are chosen) but also offers a few surprises: 
- the slight over-representation of the European group-both in terms of 2008 shares and projections for 2020 masks the considerable over-representation the smaller European countries in the original EU and the under-representation of the Central and Eastern European countries.

- a fact at odds with much of the conventional wisdom on governance reform is that the African grouping is now considerably over-represented and is projected to remain so through 2020 - both in terms population vs. UN shares and GDP vs. Bretton Woods shares. This in spite of South Africa being included in the Africa group, not having qualified individually under the $2 \%$ rule (or even a $1.5 \%$ alternative).

- the East Asia/Pacific group is adequately represented now in economic terms (vs. Bretton Woods shares) and would remain in balance through 2020.

- the Americas and MENA/South Asia groupings are now over-represented in economic terms but would seem to be roughly in balance by 2020 .

Regional groupings will of course face their own internal representation challenge. The exact mechanism for each country within the groupings could be through determined by some constituency, rotating system or other system acceptable to them-possibly even differing across regions-but is beyond the scope of this paper. 
Figure 6: Regional Groupings Voting Shares vs. Bretton Woods and UN shares - 2008 and 2020 (GDP and population shares vs. current voting shares)
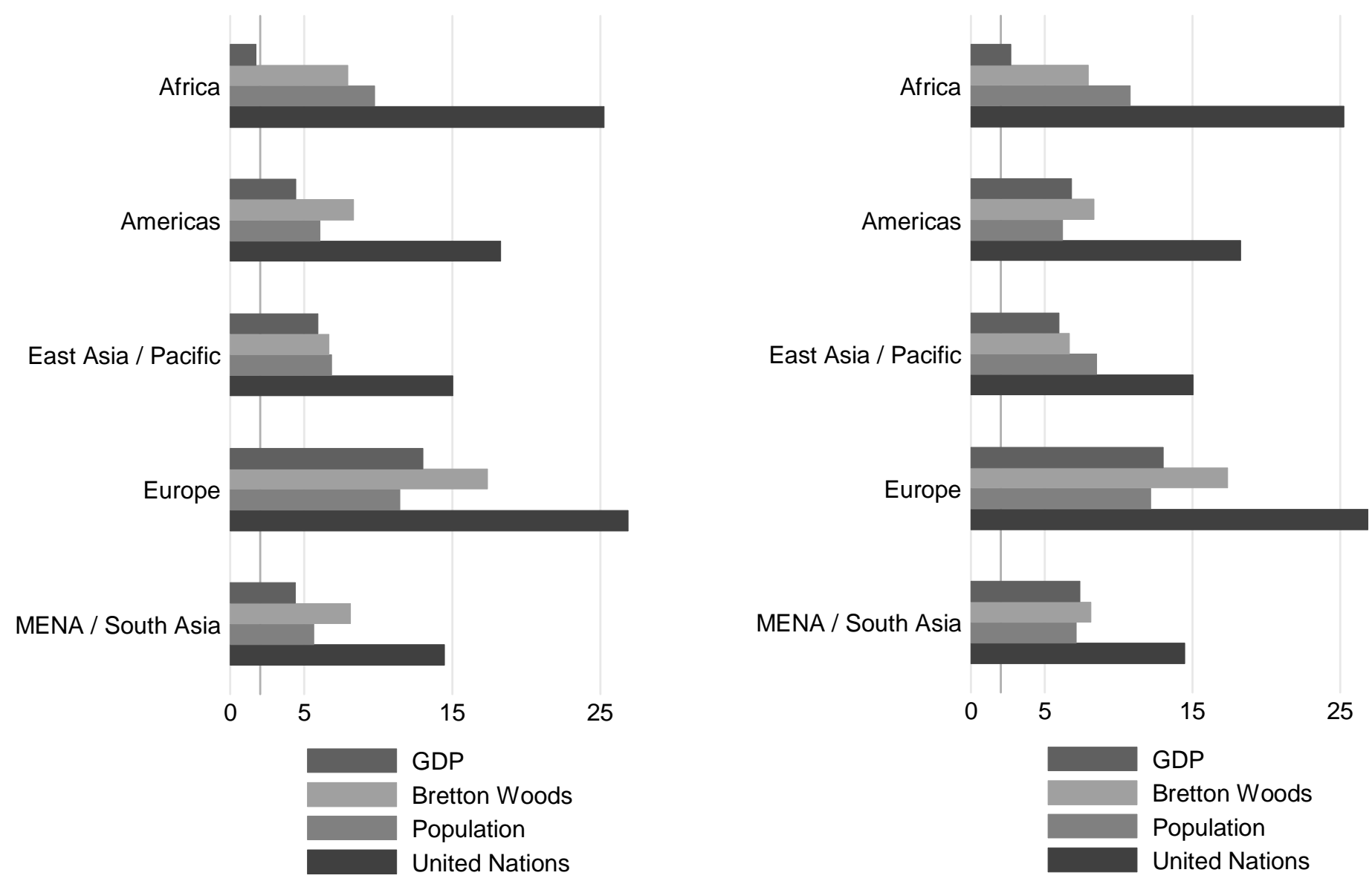

The situation we describe here should not be news to anyone, but facts do have a tendency to make us face disparities that are obscured by familiarity. What this analysis reminds us of is that:

- The UN General Assembly was never democratic, or meant to be--its logic is primarily statocratic. But it has nonetheless become less and less democratic as new, smaller states have been added to the roster of UN members, diluting the voting shares of the countries with largest populations. There are no proposals under consideration that we know of to make the UN General Assembly more democratic. The UN Security Council, of course was never deemed democratic, and pragmatically must reflect other considerations — see for example, Dervis' emphasis on the military factor. 
- Proposals under consideration for governance reform in the Bretton Woods institutions suffer not only from incrementalism but from internal rules that are designed to preclude major changes in voting power (losers essentially would have to agree to relinquish power). Proposals in the works are also a peculiar mix of formal marginal reductions in the gap in economic representation (primarily by offering BRICs more voting shares) with an increased statocratic bias in the informal mechanism of Executive Director chairs assignments (for example, by adding one more Africa chair at the World Bank).

- Other, more informal, mechanisms do not fare any better. The G7 is fast losing global relevance and the G20, while a considerable improvement, seems also to be driven by a "host bias" and does not yet offer a sound, transparent logic for sustainable representation (see Appendix 2).

Finally, in a different realm, the OECD provides another example of the limits of incrementalism, and the paradox of institutional potential and inertia. Although not a traditionally considered a global governance mechanism, it is often included in this space (represented at Bretton Woods meetings, influential through its independent analytical and standard-setting work, etc.). But encumbered by a "club" membership that has lost its original raison d'être (and risks becoming obsolete), the OECD started to take steps adding to its membership list on an incremental basis and giving a greater role to its "Development Center" that focuses on relationships with "non-members." Appendix 3 summarizes the state of the OECD and its ad hoc (by invitation) approach to membership expansion.

This analysis of disparities points to the need for much-more-than-incremental solutions limited by the statutory confines of individual institutions. Governance systems have been left grossly out of balance by a combination of inherent flaws and of changes that have already taken place in the world (in both economic and demographic terms)—with more to come soon!

\section{Conclusion}

Naturally, much attention is now focused on the immediate financial (and accompanying economic) crisis. But the crisis has also underscored the extent of interdependence in the world and the need for a much better way of managing financial interdependence. Thus far, all that could be mustered was an ad hoc meeting of the G20 upgraded to the head of government level. There is no doubt that managing interdependence among people and nations and tackling global problems-including around resource scarcities and climate change-is become an ever greater challenge and one that the world cannot afford to put on the back burner until the current crisis is over. It is also clear that providing a lasting remedy to the current situation is a tall order! What we propose here is the need for an "umbrella" mechanism for global governance that meets the criteria we outlined at the outset. This mechanism would have two sets of objectives. The first would be to immediately establish a platform for global decisions that is transparently constructed, incorporates universal representation and has access to the means required to turn decisions into action (purposes that the high-level G20 meeting in November sought to accomplish but for which that mechanism is ill-equipped). 
The second objective is to provide guidance-and pressure-for a more comprehensive reform of global governance and coherent evolution of the myriad institutions currently at play in the global arena. It is clear that the world needs different institutions with different mandates and dynamics to serve different purposes ... and that no governance blue-print will be appropriate for them all. But it is also clear that allowing all these institutions to evolve with their own limitations, vested interests and inertia will not only represent a huge missed opportunity but will also hobble global governance in the long term.

In the absence of an umbrella mechanism to ensure coherence and momentum, it is very possible that the small wins of incremental improvements in each institution will result in a big loss for sustainable, effective global governance. The umbrella mechanism we envisage would play a role along the lines of a board of directors of a public holding company.

The analysis we have presented here provides an avenue for thinking about how such a system could be constructed, around a mix of representation by individual countries and regional constituencies. Consistent with the principles we outlines at the outset, a number of variations are possible. Our purpose is not to offer a final design for global governance but to create a solid basis on which to move the discussion to a higher level of ambition.

There are many assets that can be built on--these could become features of a "network" or collaborative of components of a global governance system:

- the universality of the UN General Assembly

- the work of specific UN funds and agencies

- the effectiveness and access to resources of the Bretton Woods institutions

- the think-tank credibility of the OECD

- the focus on relevant expertise (as opposed to representational turf) of the EU Council of Ministers

A new global governance system would not be cost-free. But the fact is that there are significant financial and human assets in various parts of the existing multilateral and quasi-global governance system that are currently being underutilized (in some cases grossly underutilized).

There is a huge opportunity for improving cost-benefit ratios of existing institutions and for removing the inertia that currently exists within each, along with the vested interests that have captured different pieces. The staggering amount of money (hundreds of millions of euro) involved in maintaining pro-forma, resident 'executive' boards at the Bretton Woods institutions and of large UN delegations (products of an era before the jet plane, telecommunications and the power of the Internet) could be used for much better purposes, for instance, as could the resources of agencies often forgotten after the initial momentum or constituency for their creation has been exhausted and with no obvious mechanisms for overhauling or closure.

On the basis of existing assets, one could envisage much leaner, specialized multilateral institutions, networks of national and international experts, a basic structure of governance with actual participation derived from domain expertise-for example, agriculture officials meeting to discuss issues in their domain, rather than diplomats expounding on world economics in the UN's Third Committee etc. 
This new system can draw on 'new age' organizational and technological mechanisms. In the era of the Internet and Web 2.0 there is huge opportunity for improving collaboration, effectiveness and transparency. Technology is available to develop creative virtual networks dramatically increasing the scale and speed of efforts to seek solution to urgent global or local problems and offering options with much-reduced costs for managing interdependence. The collaborative culture that it makes possible could thrive on a platform for global governance that is transparent and credible. 
Appendix 1: Implications of a Lower Threshold-a 1\% Club of Governance

Let us examine, in the spirit of sensitivity analysis, the implications of a lower threshold. The group of countries that accounts for over 1 percent of GDP or population includes an additional 10 countries in 2008 and another 15 countries to the 2020 grouping at the $2 \%$ threshold. It is interesting to look at these additional countries - the Philippines, Egypt and Vietnam enter the group in 2008 and 2020 and Iran enters the group along with Poland, Romania and the Democratic Republic of Congo in 2020. But several countries are still left out.

Including these extra countries would raise the proportions of GDP and population accounted for by the "core" group to 83 percent of GDP in 2008 and 75 percent of population; these numbers are slightly higher for 2020 (see table below). But this lower threshold increases the size of the group with exponential consequences for its group dynamics. It also reduces the share of noncore countries to the point where the rationale for regional representation erodes significantly.

GDP and Population Shares at a Lower Threshold

\begin{tabular}{|l|l|l|l|}
\hline $\begin{array}{l}\text { GDP or } \\
\text { Population }>2 \% 08\end{array}$ & $\begin{array}{l}\text { GDP or } \\
\text { Population } \\
\begin{array}{l}<\% \text { and } \\
<2 \% \text { in 2008 }\end{array}\end{array}$ & $\begin{array}{l}\text { GDP or } \\
\text { Population }>2 \% \\
\text { in 2020 }\end{array}$ & $\begin{array}{l}\text { GDP or Population } \\
>1 \% \text { and }<2 \% \text { in } \\
2020\end{array}$ \\
\hline Bangladesh & Turkey & Bangladesh & (additional) \\
\hline Brazil & Iran & Brazil & Iran \\
\hline Canada & Philippines & China & Netherlands \\
\hline China & Egypt & France & Poland \\
\hline France & Ethiopia & Germany & Romania \\
\hline Germany & Vietnam & India & South Korea \\
\hline India & Australia & Indonesia & Saudi Arabia \\
\hline Indonesia & Mexico & Italy & Turkey \\
\hline Italy & South Korea & Japan & Congo DR \\
\hline Japan & Netherlands & Nigeria & Egypt \\
\hline Nigeria & & Pakistan & Ethiopia \\
\hline Pakistan & & Russia & Vietnam \\
\hline Russia & & Spain & Philippines \\
\hline Spain & & UK & Canada \\
\hline UK & & US & Mexico \\
\hline US & & & \\
\hline $72 \%$ GDP & $10.65 \%$ GDP & $66 \%$ GDP & $16.22 \%$ GDP \\
\hline $65 \%$ Population & $10.52 \%$ & $63 \%$ Population & $13.67 \%$ Population \\
\hline Population & & \\
\hline & & & \\
\hline
\end{tabular}


Appendix 2: The 2\% Club vs. the G-20

How does the current system of the G20 fare vs. the mechanism identified in this analysis? The official website of the G20 states that "the members of the G-20 are the finance ministers and central bank governors of 19 countries: Argentina, Australia, Brazil, Canada, China, France, Germany, India, Indonesia, Italy, Japan, Mexico, Russia, Saudi Arabia, South Africa, South Korea, Turkey, the United Kingdom and the United States of America. The European Union is also a member, represented by the rotating Council presidency and the European Central Bank...The G-20 thus brings together important industrial and emerging-market countries from all regions of the world. Together, member countries represent around 90 per cent of global gross national product, 80 per cent of world trade (including EU intra-trade) as well as two-thirds of the world's population. The G-20's economic weight and broad membership gives it a high degree of legitimacy and influence over the management of the global economy and financial system."

Table 4: The $2 \%$ Club vs. the G20

\begin{tabular}{|l|l|l|}
\hline $\begin{array}{l}\text { GDP or } \\
\text { Population }>2 \% \\
\text { in 2008 }\end{array}$ & $\begin{array}{l}\text { GDP or } \\
\text { Population }>2 \% \\
\text { in 2020 }\end{array}$ & Current G-20 \\
\hline Bangladesh & Bangladesh & Argentina \\
\hline Brazil & Brazil & Australia \\
\hline Canada & China & Brazil \\
\hline China & France & Canada \\
\hline France & Germany & China \\
\hline Germany & India & France \\
\hline India & Indonesia & Germany \\
\hline Indonesia & Italy & India \\
\hline Italy & Japan & Indonesia \\
\hline Japan & Nigeria & Italy \\
\hline Nigeria & Pakistan & Japan \\
\hline Pakistan & Russia & Mexico \\
\hline Russia & Spain & Russia \\
\hline Spain & UK & Saudi Arabia \\
\hline UK & US & S.Africa \\
\hline US & & S.Korea \\
\hline & & Turkey \\
\hline & & UK \\
\hline & & EU-21countries \\
\hline
\end{tabular}

Recent proposals argue that the G20 forum should be turned into a more long-lasting feature of global governance (Bradford, Linn and Martin, 2008). But the case for this is not strong. Very large countries like Bangladesh or Nigeria are missing-which cripples democratic representation. Furthermore, the Europe-heavy nature of the G20 is probably not a good way to manage the world in 2008 or in the future. The official website of the G20 states that it accounts 
for 90 percent of the world's GDP. But this is accomplished by counting all of the EU countries as being in the G20 (simply because the European Union is represented). This incidentally, is not how the 21 members of the EU not directly represented in the G20 see it-Spain's (rightful) insistence at being present at the G20 summit in Washington this past November turned into something of a national fixation (International Herald Tribune, November 6 2008). 
Appendix 3: The Incrementalist Approach of the OECD—Membership Then and Now

\begin{tabular}{|l|l|l|l|l|}
\hline $\begin{array}{l}\text { OECD } \\
1960 \mathrm{~s}\end{array}$ & 1970s & 1990s & $\begin{array}{l}\text { Invitations of } \\
\text { membership } \\
\text { (2007) }\end{array}$ & $\begin{array}{l}\text { Invitations of } \\
\text { "Enhanced } \\
\text { Engagement” } \\
\text { (2007) }\end{array}$ \\
\hline Austria & Australia & Czech Republic & Chile & Brazil \\
\hline Belgium & New Zealand & Hungary & Estonia & China \\
\hline Canada & & Korea & Israel & India \\
\hline Denmark & & Mexico & Russia & Indonesia \\
\hline France & & Poland & Slovenia & South Africa \\
\hline Germany & & & & \\
\hline Greece & & & & \\
\hline Iceland & & & & \\
\hline Ireland & & & & \\
\hline Luxembourg & & & & \\
\hline Netherlands & & & & \\
\hline Norway & & & & \\
\hline Portugal & & & & \\
\hline Spain & & & & \\
\hline Sweden & & & & \\
\hline Switzerland & & & & \\
\hline Turkey & & & & \\
\hline United Kingdom & & & & \\
\hline United States & & & & \\
\hline
\end{tabular}

From the official OECD website:

Extract from the Council Resolution on Enlargement and Enhanced Engagement (adopted by Council at Ministerial level on 16 May 2007):

The Council

i) Invites the Secretary-General to strengthen OECD co-operation with Brazil, China, India, Indonesia and South Africa through enhanced engagement programs with a view to possible membership. The Council will determine whether to open discussions on membership in light of the willingness, preparedness and ability of these countries to adopt OECD practices, policies and standards.

ii) Decides to open discussions with Chile, Estonia, Israel, the Russian Federation and Slovenia and invites the Secretary-General to set out the terms, conditions and process for the accession of each of these countries to the OECD for subsequent consideration and adoption by Council. Separately, Council may raise issues of a political nature which the Secretary-General will 
convey to the countries concerned in the context of the discussions on accession.

iii) Invites the Secretary-General to inform other countries that have applied for membership that their applications for accession shall be further considered individually by Council as enlargement proceeds; future applications shall be similarly considered.

iv) Invites the Secretary-General to explore and develop recommendations to Council on how to expand the OECD's relations, including through enhanced engagement, with selected countries and regions of strategic interest to the OECD, identified by Council. In light of its growing importance in the world economy, priority will be given to South East Asia with a view to identifying countries for possible membership.

v) Invites the Secretary-General to report regularly to the Council on the progress of his discussions and consultations with the countries above and outline options for the OECD's further relationship with these countries. In outlining such options, due consideration will be given to the capacity of the Organisation to process potential candidates without affecting the regular programme of work. 


\section{References}

Bradford, Colin, Johannes Linn and Paul Martin (2008), “Global Governance Breakthrough: The G20 Summit and the Future Agenda,” Brookings Policy Brief \#168.

Birdsall, Nancy (2007) “The World Bank: Toward a Global Club,” in Colin I. Bradford, Jr. and Johannes F. Linn (eds), Global Governance Reform: Breaking the Stalemate, Washington DC: Brookings Press, pp. 50-59.

Chowla, Peter, Jeffrey Oatham and Claire Wren, "Bridging the democratic deficit: Double majority decision making and the IMF,” Briefing, Bretton Woods Project, February 2007

Dervis, Kemal with Ceren Ozer (2005). A Better Globalizaton: Legitimacy, Governance and Reform, Washington DC: Center for Global Development.

Geldof, Bob (2008) "Remember the bottom billion in our brave new world,” Financial Times, November 13.

International Herald Tribune, "Spain wants to go to Washington for financial meeting," November 6, 2008.

Mattoo, Aditya and Arvind Subramanian, “India and Bretton Woods II,” Economic and Political Weekly, November 8, 2008.

Official G20 website. www.g20.org

Official OECD website. www.oecd.org

Traub, James (2009), “Shaking Up the Boardroom at World Government Inc.,” The New York Times, January 4, 2009.

Zakaria, Fareed (2008). The Post-American World, (New York: W.W. Norton). 